\title{
Spatial distribution of leprosy in Brazil: a literature review
}

\author{
Cláuffer Luiz Machado Silva ${ }^{[1]}$ Sandra Costa Fonseca ${ }^{[1]}$ Helia Kawa ${ }^{[1]}$ \\ and Dayanna de Oliveira Quintanilha Palmér ${ }^{[2]}$
}

[1]. Programa de Pós-Graduação em Saúde Coletiva, Instituto de Saúde Coletiva, Universidade Federal Fluminense, Niterói, RJ, Brasil.

[2]. Faculdade de Medicina, Universidade Federal Fluminense, Niterói, RJ, Brasil.

\begin{abstract}
Leprosy remains a public health problem in developing countries. Among communicable diseases, it is one of the leading causes of permanent disability. Brazil had not reached the goal of reducing cases to less than 1 per 10,000 population. This study aimed to analyze the spatial distribution of leprosy cases in Brazil, using a literature review. The search strategy included the LILACS and MEDLINE databases with no language or period restriction. Ecological studies with spatial data analysis were considered as a criterion for the inclusion. We found 38 studies for review after the selection criteria. Among the epidemiological indicators of the disease, the most common was the new case detection rate. Several articles have explored the association between spatial distribution of leprosy and socioeconomic, demographic, and environmental factors. The most common unit of analysis was the municipality. The spatial distribution methods mostly used were: empirical Bayesian method, autocorrelation (Moran's I index) and Kernel estimates. The distribution of leprosy was very heterogeneous, independent of the unit of analysis. There was a decrease in the rate of detection and among under-15-year-olds, but some regions maintained high endemicity during the study period. The distribution and risk of illness were directly related to living conditions of the population. Improved access to health services was associated with increased detection rate in some regions. Spatial analysis seems to be a very useful tool to study leprosy and to guide interventions and surveillance.
\end{abstract}

Keywords: Leprosy. Brazil. Spatial analysis. Review.

\section{INTRODUCTION}

Leprosy is still a public health problem in low and middleincome countries. It is a leading cause of permanent disability and social stigma ${ }^{1}$, and stands out as one of the neglected infectious diseases in those countries. Despite the magnitude and impact on health, leprosy has little investment regarding therapeutic research and development ${ }^{2,3}$.

Economic, political, social, and demographic changes that occurred during the last 40 years in Brazil impacted the social determinants of health in the country ${ }^{4}$. Consequently, the incidence of infectious diseases declined, but the impact on leprosy is not yet fully clear ${ }^{5,6}$. Studies point out that cash transfer policies were related to the decrease in disease incidence, while the expansion of the Family Health Care Strategy improved the detection of new cases $^{6,7}$.

In 2015, 28,761 new cases were reported, corresponding to a case detection rate (CDR) of 14.07/100,000 inhabitants, which is considered high. Brazil is about to reach the World Health Organization's target of control, but 535 municipalities are still

Corresponding author: Msc. Cláuffer Luiz Machado Silva e-mail: claufferluiz@hotmail.com

Received 13 August 2016

Accepted 23 June 2017 classified as hyperendemic, with CDRs higher than 40/100,000 inhabitants ${ }^{8}$. The geographical distribution of leprosy is uneven and the disease persists in regions with higher levels of poverty and malnutrition, showing a close relationship with precarious conditions of living, low educational level, social inequality, and also with migratory movements ${ }^{9,10}$.

To best understand the differences in the distribution of infectious diseases, ecological studies with spatial data analysis have increased during the past 30 years in Brazil ${ }^{11}$. Different spatial scales were taken into account, usually with geographic and administrative references, such as states and administrative districts. Other potential spatial units of data aggregation are the census sector, neighborhood, hydrographical basin, and sanitary district ${ }^{12}$.

In this context, we reviewed the spatial distribution of leprosy and methods used for spatial analysis in Brazil, according to different scales, and its relationship with demographic and socioeconomic factors.

\section{METHODS}

We performed a literature review, according to the recommended steps for systematic reviews, except for quantitative analysis (meta-analysis) ${ }^{13}$.

The bibliographical search was performed in the Latin American and Caribbean Literature on Health Sciences 
(LILACS) and Medical Literature Analysis and Retrieval System (MEDLINE) databases. In the LILACS database we combined the descriptors Spatial Analysis, Analysis by Conglomerates, Spatial Distribution of the Population, Ecological Study, Geographic Information System, with leprosy and Brazil, using the Boolean operator $A N D$. Each combination was done separately, as the system did not accept merging the syntax terms with the operator $O R$.

In the MEDLINE database, we used the syntax leprosy AND (Spatial Analysis OR Cluster Analysis OR Residence Characteristics OR Ecological Studies OR Geographic Information Systems) AND Brazil.

There was no restriction on language or publication period. The lists of references in the identified articles were searched to identify items not captured in the electronic search. The search was conducted in 2015 and updated in March 2016.

The paired review system was used in the selection of articles; two researchers evaluated the titles to be included in the abstracts to be read. At least one author approved the titles to increase the sensitivity at this stage. After reading the abstracts of the articles, those approved by both authors were included to be read in full. When there were divergent views, a third researcher read the summary to give an opinion before exclusion.

Ecological studies with spatial data analysis were included in the study; those articles not assessing the spatial distribution of the disease were excluded.

\section{RESULTS}

Using the established bibliographical review criteria, 35 studies were selected (Figure 1): 35 articles.

Table 1, Table 2 and Table 3 show the articles' summaries according to the scale used: two evaluated regions/ mesoregions ${ }^{14,15} ; 13$ used the scale of municipalities ${ }^{10,16-27} ; 4$ evaluated districts ${ }^{28-31} ; 6$ studied neighborhoods ${ }^{32-37} ; 7$ analyzed the census tracts ${ }^{38-44}$; and 3 investigated households ${ }^{45-47}$. Within each scale, the articles were organized by location: Brazil, Northern, Northeast, Midwest, and Southeast regions. In all, 4 approached Brazil ${ }^{10,16-18}$, 7 studied the Northern region or the states of the Amazon region ${ }^{14,19,20,38-40,45}, 11$ focused on the Northeast region ${ }^{21-23,28,32-36,40,41}, 4$ the Midwest region ${ }^{15,29,37,46}$, and 12 the Southeast region ${ }^{24-27,30,31,36,37,42-44,47}$.

As a data source for the cases of leprosy, the Notifiable Diseases Information System (SINAN) was hegemonic, and among the epidemiological disease indicators, the most widely used was the new case detection rate (NCDR) in the population without distinction by age group. Seven studies ${ }^{10,19,20,23,32,33,36,38}$ evaluated the NCDR indicator of individuals under 15 years of age, 3 evaluated the disability-degree indicator ${ }^{19,20,22}$ and one article explored the spatial distribution of mortality due to leprosy ${ }^{18}$.

Some studies showed descriptive data of spatial distribution, while others looked into socioeconomic, demographic and environmental conditions that could contribute to the

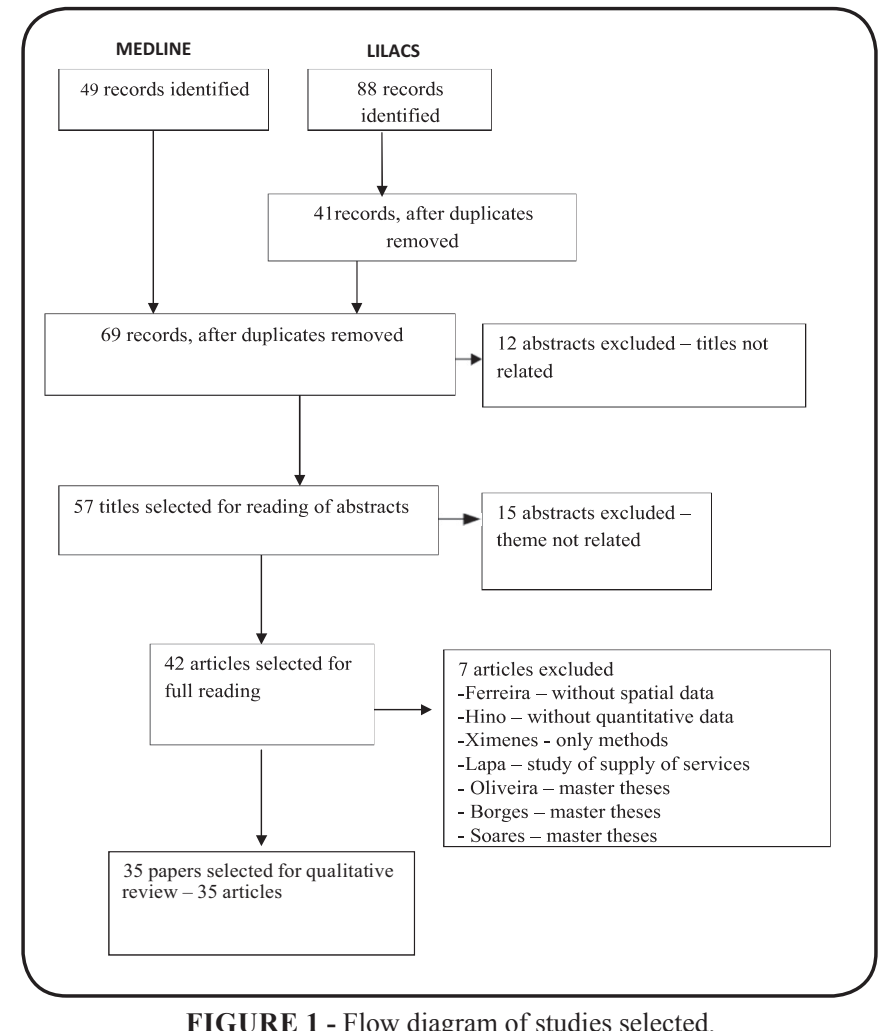

understanding of the spatial distribution of leprosy. The socioeconomic variables mostly evaluated were income, education, sanitation conditions, number of residents per house - individually or as composite indicators, such as the social deprivation inde $\mathrm{x}^{42}$. For these indicators, the most used data source was the Brazilian Institute of Geography and Statistics (IBGE). Two of the articles used the Gini index ${ }^{17,23}$ as a measure of inequality. Regarding demographic conditions, population density was studied (on the scales of neighborhoods and census sectors), as well as the level of urbanization. The distance between households was also studied, and as an environmental condition, deforestation was evaluated in two articles ${ }^{14,15}$.

The most commonly used methods of spatial analysis were the following: empirical Bayesian method, autocorrelation (Moran index) to verify the existence of spatial conglomerates (clusters), and Kernel estimates to show areas with greater intensity (hot spots). Kriging methods and scan tests were also used. The two studies ${ }^{14,15}$ that covered mesoregions and microregions have shown a correlation between the evolution of deforestation and an increase in NCDR, besides the effect of migration movements on coefficients of detection and focuses (new and old) of the disease.

In the analyses by municipalities, three studies examined the NCDR of the country at different moments in time ${ }^{10,16,17}$, and showed concentration in the North and Midwest regions, and in the Northeastern states located in Legal Amazon. The study by Freitas et al. ${ }^{17}$ looked at risk factors, estimated rate ratios (RR), and identified a high NCDR in the Midwest and North regions compared to the South, large cities and greater urbanization, median and high illiteracy rate, 


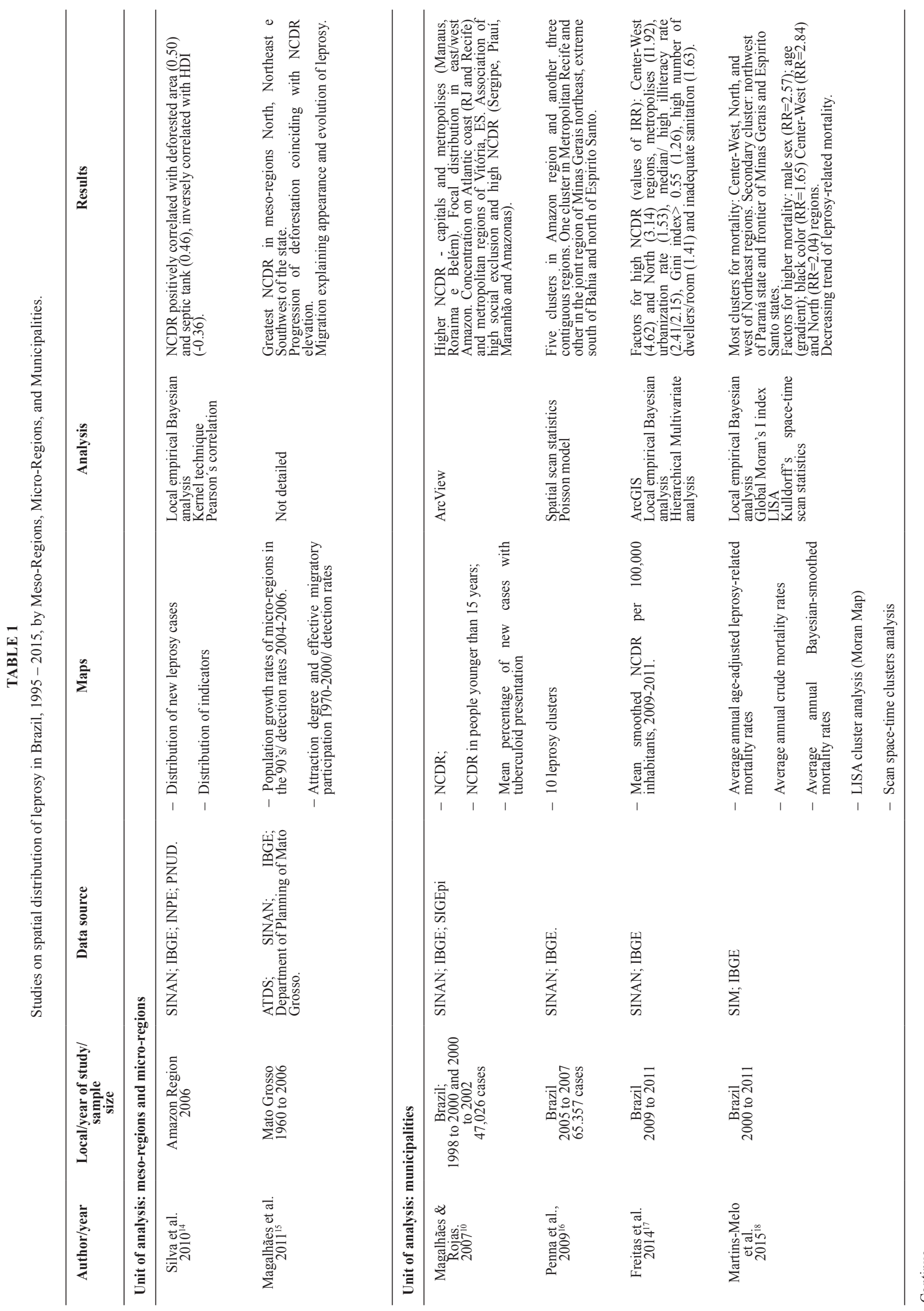




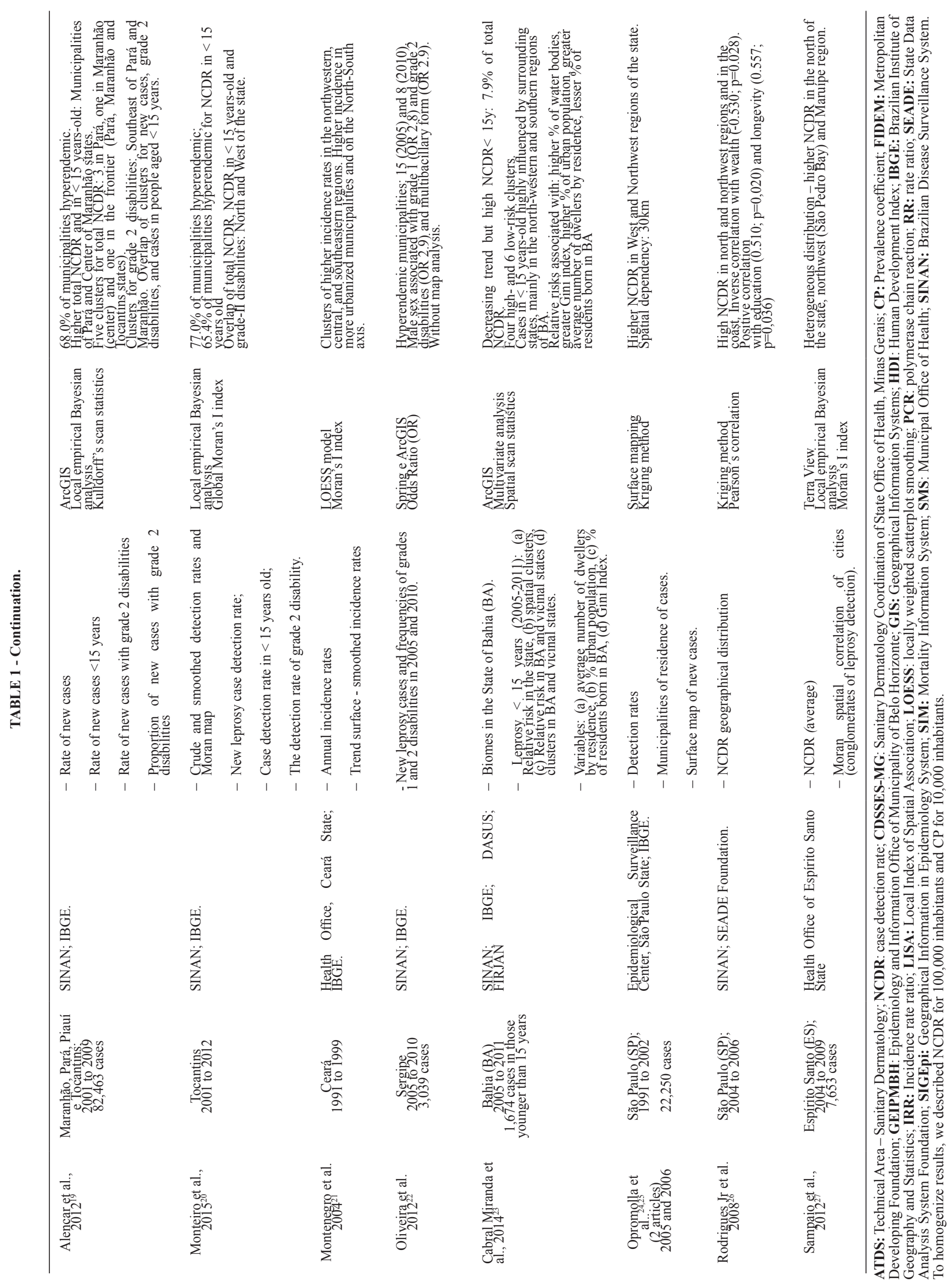




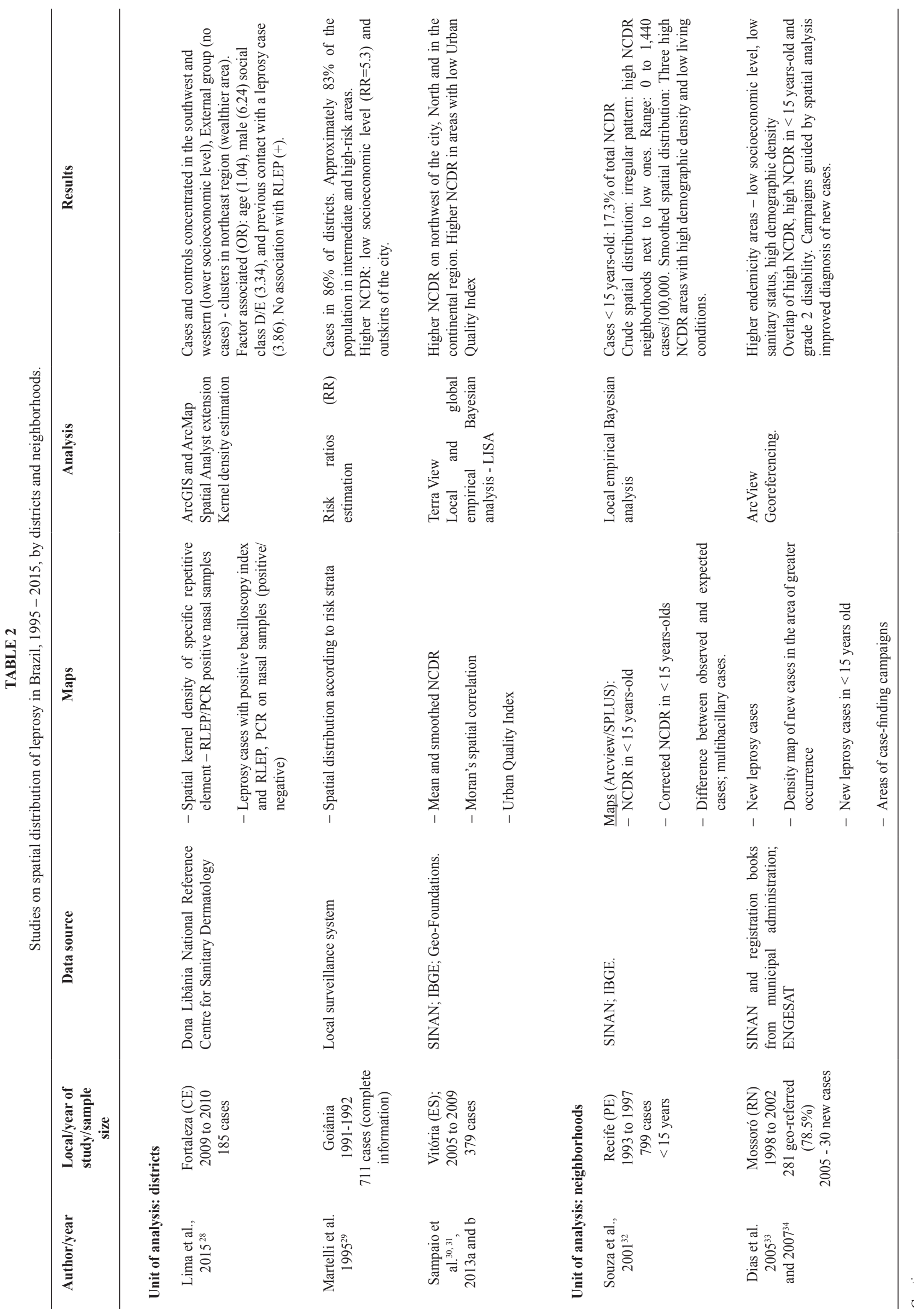




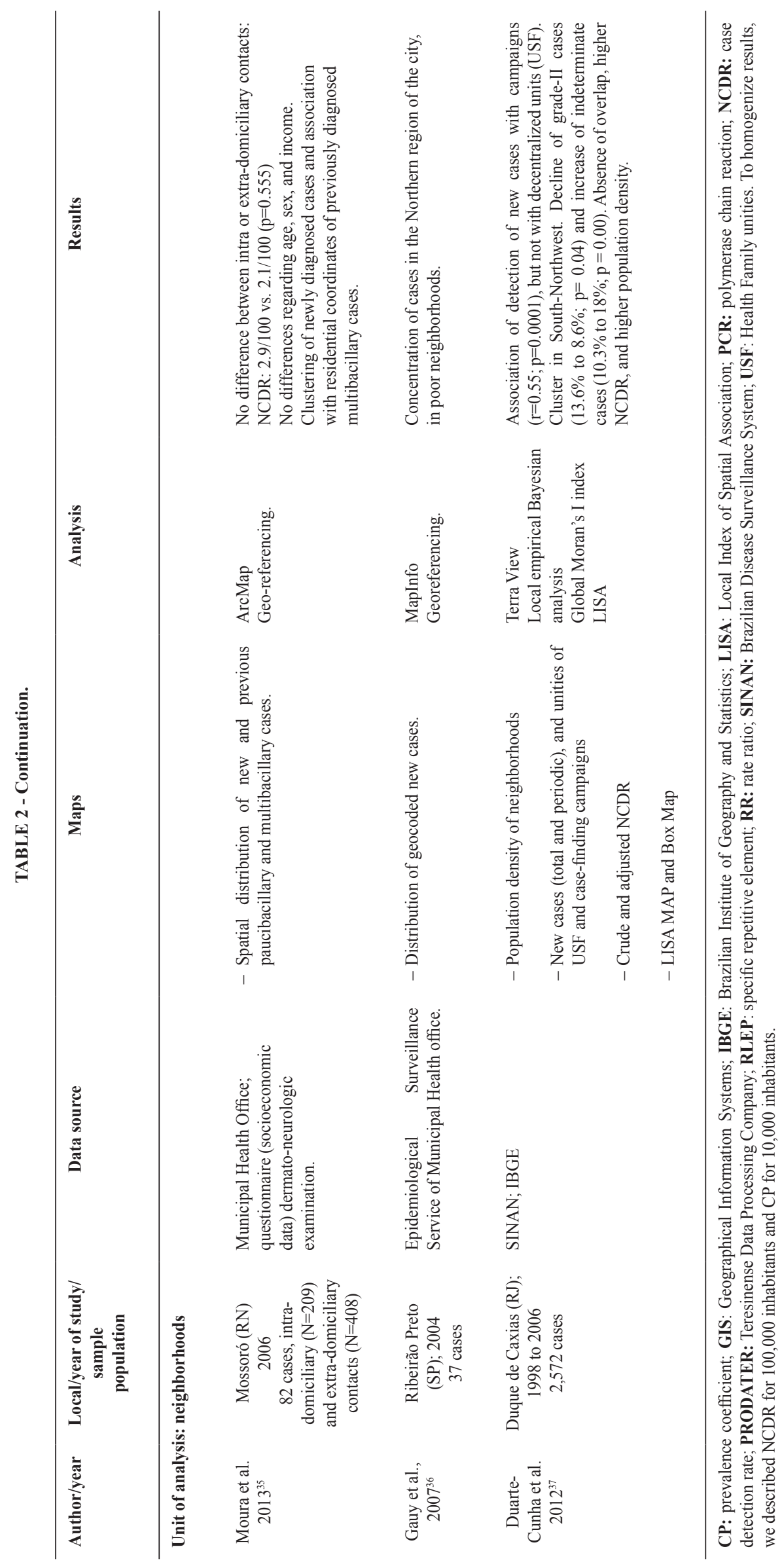




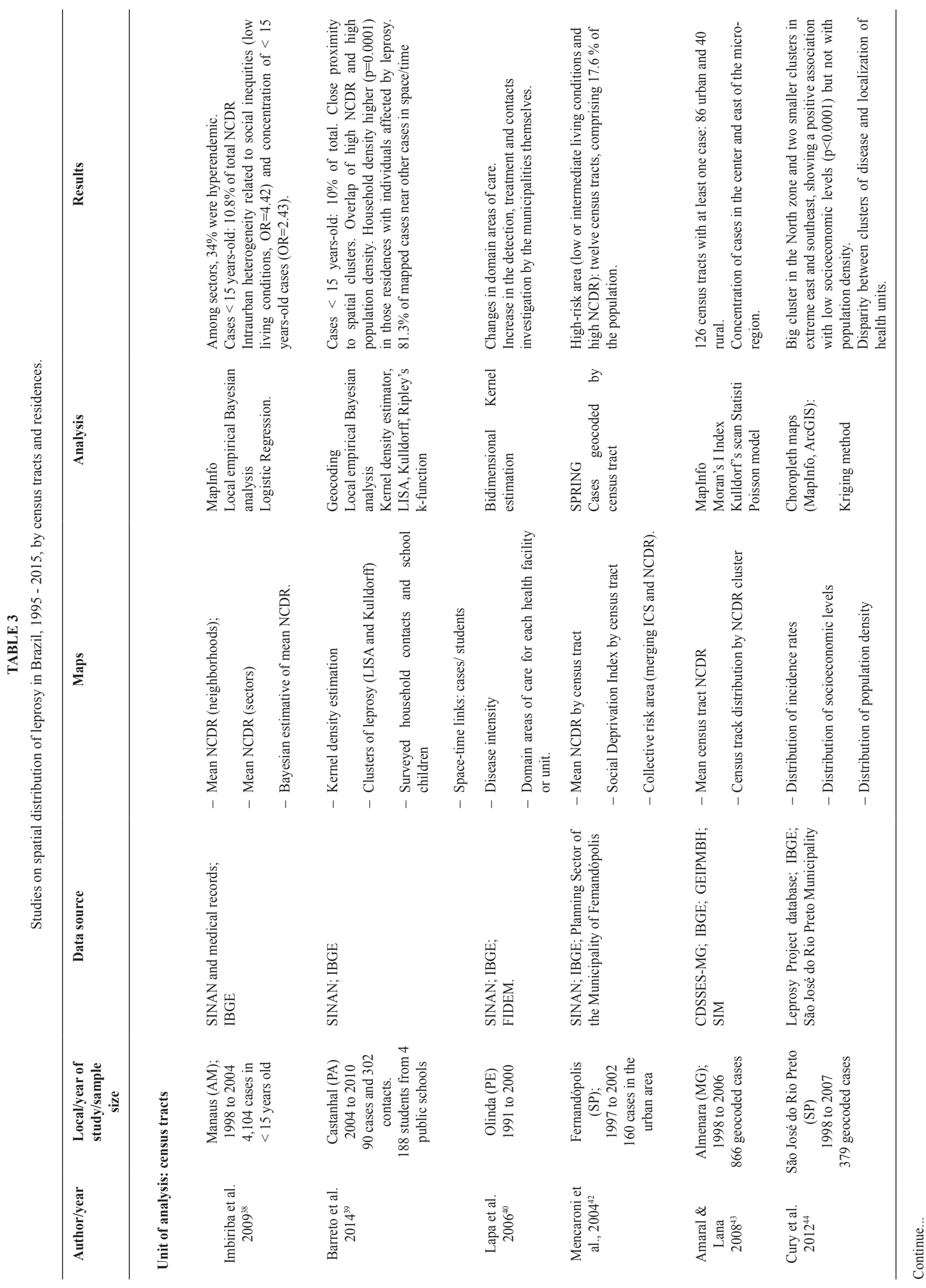




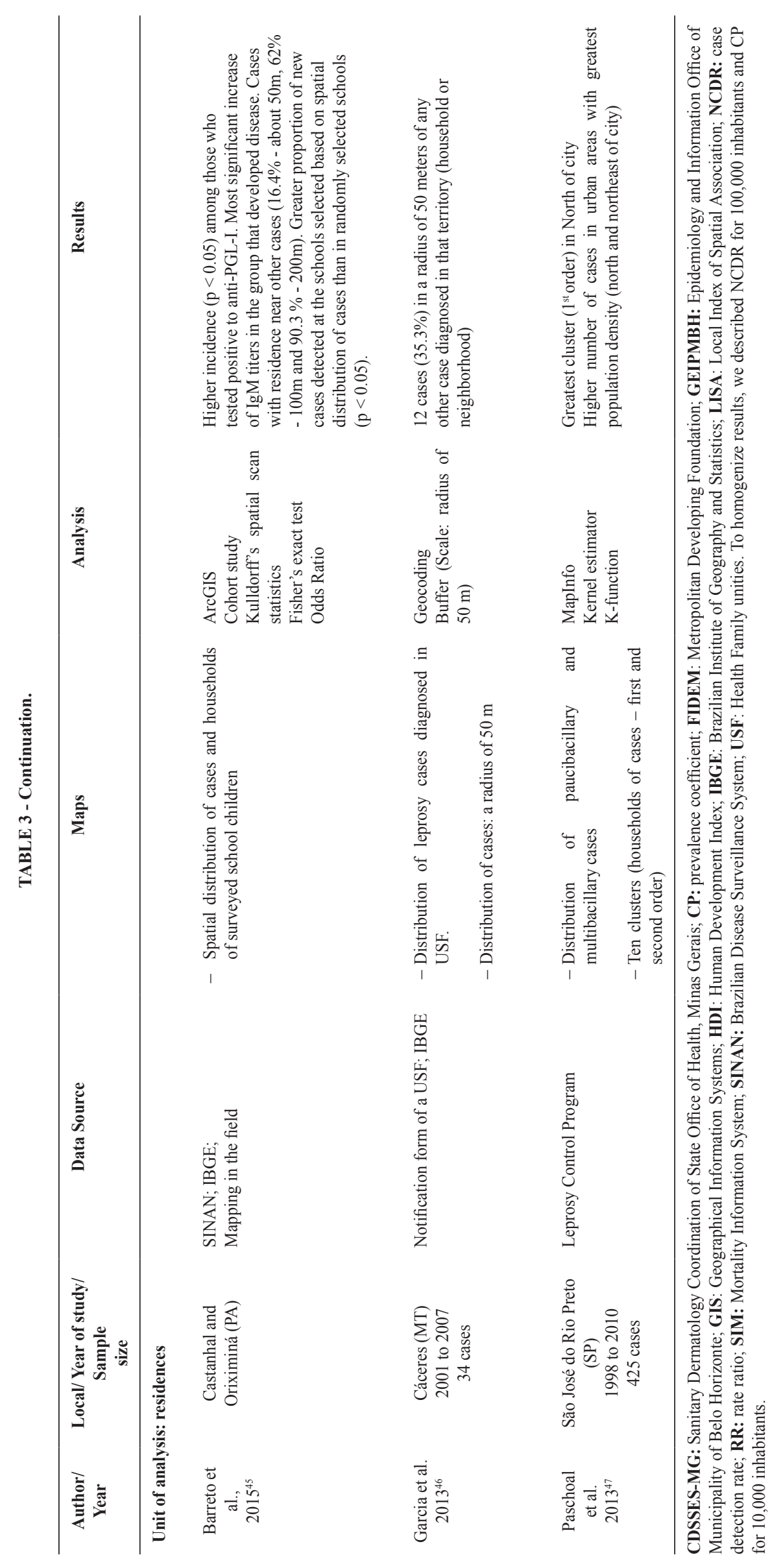


income inequality (Gini index), domiciles' agglomeration, worse sanitation condition, and percentage of cases with grade 2-disability.

Regarding health care indicators, there was an association between an increased Family Health Care Program coverage and the number of contacts investigated. The study by Martins-Melo et al. was the only one that evaluated the spatial distribution of mortality due to leprosy ${ }^{18}$. Both crude and smoothed rates showed greater mortality in the Midwest and North regions, in black individuals, in males, and had a gradient relationship with aging. High mortality clusters were identified in the Midwest, North and Northeast regions, as well as Northwest of Paraná State.

Mortality decreased in Brazil from 2000 to 2011, but has remained stable in North and Northeast regions. Other studies using the scale of municipalities identified clusters and heterogeneity in the distribution of the disease associated with low socioeconomic indicators ${ }^{23,26}$ and increased urbanization ${ }^{21,23}$, apart from indicators that overlap with high values - global NCDR, NCDR in children under 15 years, and grade 2 disability ${ }^{19,20}$. In the Northern region and the Amazonian States, high percentages of hyperendemic municipalities (NCDR $>40 / 100,000$ inhabitants) were accentuated.

Regarding districts, areas with greater detection rates for leprosy corresponded with lower socioeconomic status, measured by social class and urban quality inde ${ }^{28,31}$. The study by Lima et al. was the only one that assessed the carrier status, and used a case-control approach, besides an external group. Spatial distribution of carriers was also characterized by clusters ${ }^{28}$.

In the analysis by neighborhood, heterogeneity was also partly explained by low socioeconomic pattern ${ }^{32-34}$, basic sanitation deficit ${ }^{33,34}$, and high population density ${ }^{32-34}$.

Studies in Mossoró (Rio Grande do Norte state) have used geographic information systems to guide case-finding campaigns ${ }^{33,34}$. In the scale of census tracts, it was observed that low socioeconomic levels ${ }^{42,44}$ and high population density $\operatorname{areas}^{39,41}$ showed a positive association with higher incidence.

The study by Imbiriba et al. refined the analysis with data on occupation from different census tracts, showing that migration and great poverty contributed in different parts of Manaus $^{38}$ (Amazonas State). In Castanhal (Pará State), Barreto et al. described the distribution of houses and investigated contacts, and the relationship with serological levels of antiphenolic glycolipid-I (anti-PGL-I) ${ }^{39}$. The studies that observed households ${ }^{45-47}$ or schools identified that new cases emerged in small distances of cases previously diagnosed ${ }^{45,46}$, and clusters of disease were located in poorer areas and those with higher population densities ${ }^{47}$.

\section{DISCUSSION}

We have identified 35 studies on the spatial distribution of leprosy in the last 20 years. Although the most affected areas were the North and the Midwest, the scientific literature was not proportional to the intensity of the disease; almost a third of the studies were carried out in the Southeast region. Probably the proximity of research institutions accounted for this disproportion.

Most articles used the SINAN as a source of information; however, it is known that there are problems of completion and consistency in this system ${ }^{48,49}$. Another point to be considered is the difficulty experienced by various authors in making geographical references of leprosy cases, because of the incompleteness of the addresses in the SINAN, or insufficient information. Such instances were more frequent on the outskirts of the cities, where the NCDR was higher and it would be more relevant to obtain this information ${ }^{37,40}$. Most of the authors used the local Bayesian empirical model to smooth the leprosy detection coefficients in an attempt to alleviate random fluctuations in the indicators, a consequence of rare events in small population $\mathrm{s}^{50}$. Smoothing of detection rates can improve early detection of cases, increase the number of regions classified as hyperendemic and the number of people needed to be followed to detect one new case of leprosy $y^{39,45}$.

Also, the combination of geographic information systems and spatial analysis can identify clustering of leprosy cases, select areas for more focused interventions, and monitor disease control ${ }^{51}$. We must highlight that heterogeneity was observed in the distribution of the disease in all scales used, regardless of the analytical method used.

The epidemiological indicator most used was the NCDR. Despite the high levels of leprosy in children aged less than 15 years in the country and the importance of the degree of disability to identify diagnosis delay, few studies have addressed these indicators. For all indicators, the results showed that despite the decrease in the number of leprosy cases reported in temporal studies in the country ${ }^{7,52}$, there are areas with stagnation or growth of these indicators. Some endemic areas showed an overlap of indicators, adding a high risk of transmission and clusters of late diagnosis ${ }^{19,29,33}$.

Some studies also evaluated contacts (intra and extradomiciliary) and the transmission of leprosy. The importance of intra-domiciliary transmission was confirmed by comparing it with the probability that multibacillary carriers will be infected even before the clinical manifestation of the disease ${ }^{17,35,46}$. Transmission was also identified in the neighborhood and school environment ${ }^{39,45}$. It must be pointed out that the study by Barreto et al. incorporated anti-PGL-I serology as an adjuvant to surveillance activities merged with spatial analysis in the early detection of new cases ${ }^{45}$.

This may be a promising approach to the strategy of active search attached to the administration of immunoprophylaxis and/or chemoprophylaxis, which are proposals to zero out the transmission of leprosy ${ }^{53}$. These authors emphasize the effectiveness of large-scale school surveys, mainly in hyperendemic areas or clusters of the disease. There is some controversy regarding health services and indicators of leprosy. Some authors ${ }^{36,37}$ report that despite the decentralization of services and leprosy control activities, as well as the increased coverage of the Family Health Care Strategy, health services are centered on passive surveillance, with less impact on the control of endemic diseases. 
As these services serve spontaneous demand patients mostly, hidden prevalence remains. In Duque de Caxias, a municipality of Rio de Janeiro ${ }^{37}$, a positive correlation between new cases and targeted campaigns showed no correlation between the number of new cases and the number of decentralized units of service for leprosy, both USF and decentralized reference units. A study on the delay in disease diagnosis in Brazil identified that misdiagnosis of cutaneous lesions is one of the predisposing factors, and recommended strengthening the medical curricula ${ }^{54}$.

On the other hand, some studies reaffirm trend evaluations, showing that the increase of NCDR related to coverage of health services does not reflect a true increase in the incidence ${ }^{40}$, but an increase in the detection of new cases that would otherwise remain undiagnosed - the hidden prevalence. However, the trend, for the next few years, would be a decrease in disease incidence ${ }^{55}$. Additionally, NCDR can vary due to distortions caused by the different qualities of municipal surveillance systems.

Furthermore, trend comparisons are certainly hampered by changing municipalities, and redefinition of geographical areas occurring in recent decades in the country, in addition to population migratory movements. Spatial analysis has contributed to the knowledge of the magnitude and dynamics of leprosy as a disease. Although the country shows decreases in prevalence and in the detection of new cases, priority regions of high endemicity were identified, where it is necessary to intensify actions to eliminate the disease.

Although the studies presented in this review are susceptible to ecological fallacy, the association of leprosy with low socioeconomic status was corroborated at different levels of spatial aggregation and with different indicators, findings similar to tuberculosis shown in a recent review ${ }^{56}$. Therefore, this confirms the importance of health policies aimed at more vulnerable populations. Another possible limitation, considering the lack of effective surveillance in low endemic areas, is the occurrence of pseudo-silent areas.

New studies with spatial analysis and geographic information systems resources ${ }^{51}$, highlighting recent transmission indicators and diagnostic delays are essential to deepen the knowledge, to guide case-finding campaigns, and to monitor interventional results in the elimination of leprosy in Brazil.

\section{Conflict of interest}

The authors declare that there is no conflict of interest.

\section{REFERENCES}

1. Organização Mundial de Saúde (OMS). Estratégia Global Aprimorada para Redução Adicional da Carga da Hanseníase (Período do Plano: 2011-2015). Brasília: Organização PanAmericana da Saúde/OMS; 2010. 34 p.

2. Ministério da Saúde (MS). Secretaria de Vigilância em Saúde. Departamento de Vigilância das Doenças Transmissíveis. Plano integrado de ações estratégicas de eliminação da hanseníase, filariose, esquistossomose e oncocercose como problema de saúde pública, tracoma como causa de cegueira e controle das geohelmintíases: plano de ação 2011-2015. Brasília: Ministério da Saúde; 2012. 100 p.

3. World Health Organization (WHO). Department of Control of Neglected Tropical Diseases Investing to overcome the global impact of neglected tropical diseases: Third WHO report on neglected diseases. Geneva: World Health Organization; 2015. 191 p. Acesso: 22 jan 2015. Available at: http://www.who.int/neglected diseases/9789241564861/en/.

4. Paim J, Travassos C, Almeida C, Bahia L, Macinko J. The Brazilian health system: history, advances, and challenges. Lancet. 2011;377(9779):1778-97.

5. Barreto ML, Teixeira MG, Bastos FI, Ximenes RA, Barata RB, Rodrigues LC. Successes and failures in the control of infectious diseases in Brazil: social and environmental context, policies, interventions, and research needs. Lancet. 2011;377(9780):1877-89.

6. Nery JS, Pereira SM, Rasella D, Penna MLF, Aquino R, Rodrigues LC, et al. Effect of the Brazilian conditional cash transfer and primary health care programs on the new case detection rate of leprosy. PLoS Negl Trop Dis. 2014;8(11):e3357

7. Andrade V, Ignotti E. Secular trends of new leprosy cases diagnosed in Brazil during 1987-2006. Indian J Lepr. 2008;80 (1):31-8.

8. Ministério da Saúde. Secretaria de Vigilância em Saúde. Portal Saúde. 2016. Hanseníase. Situação epidemiológica. Acesso: 10 jul. 2016. Disponível em: http://portalarquivos.saude.gov.br/images/ pdf/2016/julho/07/Indicadores-epidemiol--gicos-e operacionaisde-hansen--ase-2000-a-2015.pdf

9. Kerr-Pontes LR, Barreto ML, Evangelista CM, Rodrigues LC, Heukelbach J, Fieldmeier H. Socioeconomic, environmental, and behavioural risk factors for leprosy in North-east Brazil: results of a case-control study. Int J Epidemiol. 2006;35(4):994-1000.

10. Magalhães MCC, Rojas LI. Diferenciação territorial da hanseníase no Brasil. Epidemiol. Serv. Saúde. 2007;16(2):75-84.

11. Carvalho MS, Souza-Santos R. Análise de dados espaciais em saúde pública: métodos, problemas e perspectivas. Cad. Saúde Pública. 2005;21(2):361-78.

12. Barcellos CC, Sabroza PC, Peiter PC, Rojas LI. Organização espacial: saúde e qualidade de vida: análise espacial e uso de indicadores na avaliação de situações de saúde. Inf. Epidemiol. SUS. 2002;11(3):129-38.

13. Moher D, Liberati A, Tetzlaff J, Altman DG; PRISMA Group. Preferred reporting items for systematic reviews and meta-analyses: the PRISMA statement BMJ. 2009;339:b2535.

14. Silva DRX, Ignotti E, Souza-Santos R, Hacon SS. Hanseníase, condições sociais e desmatamento na Amazônia brasileira. Rev Panam Salud Publica. 2010;27(4):268-75.

15. Magalhães MCC, Santos ES, Queiroz ML, Lima ML, Borges RCM, MS Souza, et al. Migração e hanseníase em Mato Grosso. Rev Bras Epidemiol. 2011;14(3):386-97.

16. Penna MLF, Wand-del-Rey de Oliveira ML, Penna G. Spatial Distribution of Leprosy in the Amazon Region of Brazil. Emerg Infect Dis. 2009;15(4):650-2.

17. Freitas LRS, Duarte EC, Garcia LP. Leprosy in Brazil and its association with characteristics of municipalities: ecological study, 2009-2011. Trop Med Int Health. 2014;19(10):1216-25.

18. Martins-Melo FR, Assunção-Ramos AV, Ramos Jr AN, Alencar CH, Montenegro Jr RM, Wand-delRey de Oliveira ML, et al. Leprosy-related mortality in Brazil: a neglected condition of a neglected disease. Trans R Soc Trop Med Hyg. 2015;109(10):643-52.

19. Alencar CH, Ramos Jr AN, dos Santos ES, Richter J, Heukelbach J. Clusters of leprosy transmission and of late diagnosis in a highly endemic area in Brazil: focus on different spatial analysis approaches. Trop Med Int Health. 2012;17(4):518-25.

20. Montenegro ACD, Werneck GL, Kerr-Pontes LRS, Barreto ML, Feldmeier H. Spatial analysis of the distribution of leprosy in the State of Ceará, Northeast Brazil. Mem Inst Oswaldo Cruz. 2004;99(7):683-6. 
21. Monteiro LD, Martins-Melo FR, Brito AL, Alencar CH, Heukelbach J. Spatial patterns of leprosy in a hyperendemic state in Northern Brazil, 2001-2012. Rev Saúde Pública. 2015;49:84.

22. Oliveira DT, Bezerra MM, Almeida JAP, Duthie M, Reed S, Jesus AMR. Neurological disability in leprosy: incidence and gender association in Sergipe, Brazil. Geospatial Health. 2012;6(3):125-29.

23. Cabral-Miranda W, Chiaravalotti Neto F, Barrozo LV. Socioeconomic and environmental effects influencing the development of leprosy in Bahia, north-eastern Brazil. Trop Med Int Health. 2014:19(12)1504-14.

24. Opromolla PA, Dalben I, Cardim M. Análise da distribuição espacial da hanseníase no Estado de São Paulo, 1991-2002. Rev Bras Epidemiol. 2005;8(4):356-64.

25. Opromolla PA, Dalben I, Cardim M. Análise Geoestatística de casos de hanseníase no Estado de São Paulo, 1991-2002. Rev Saúde Pública. 2006;40(5):907-13.

26. Rodrigues-Junior AL, do Ó VT, Motti VG. Estudo espacial e temporal da hanseníase no estado de São Paulo, 2004-2006. Rev Saúde Pública. 2008;42(6):1012-20.

27. Sampaio PB, Rossi TL, Cerutti Jr C, Zandonade E. Spatial analysis of new cases of leprosy in the State of Espírito Santo, Brazil, between 2004 and 2009. Rev Soc Bras Med Trop. 2012;45(3):380-4.

28. Lima LNGC, Frota CC, Mota RM, Almeida RL, Pontes MA, Gonçalves HS et al. Widespread nasal carriage of Mycobacterium leprae among a healthy population in a hyperendemic region of northeastern Brazil. Mem Inst Oswaldo Cruz. 2015;110(7):898905.

29. Martelli CM, Moraes Neto OL, Andrade AL, Silva SA, Silva IM, Zicker F. Spatial patterns of leprosy in an urban area of central Brazil. Bull World Health Organ.1995;73(3): 315-9.

30. Sampaio PB, Madeira ES, Diniz L, Noia EL, Zandonade E. Spatial distribution of leprosy in areas of risk in Vitória, State of Espírito Santo, Brazil, 2005 to 2009. Rev Soc Bras Med Trop. 2013;46(3):329-34.

31. Sampaio PB, Bertolde AI, Maciel EL, Zandonade E. Correlation between the spatial distribution of leprosy and socioeconomic indicators in the city of Vitória, State of ES, Brazil. Lepr Rev 2013;84(4):256-65.

32. Souza WV, Barcellos CC, Brito AM, Carvalho MS, Cruz OG, Albuquerque MFPM, et al. Aplicação de modelo bayesiano empírico na análise espacial da ocorrência de hanseníase. Rev Saúde Pública. 2001;35(5):474-80.

33. Dias MCFS, Dias GH, Nobre ML. Distribuição espacial da hanseníase no município de Mossoró/RN, utilizando o Sistema de Informação Geográfica - SIG. An Bras Dermatol. 2005;80 (Supl 3):S289-S94.

34. D e Souza Dias MC, Dias GH, Nobre ML. The use of Geographical Information System (GIS) to improve active leprosy case finding campaigns in the Municipality of Mossoro, Rio Grande do Norte State, Brazil. Lepr Rev 2007;78(3):261-69.

35. Moura MLN, Dupnik KM, Sampaio GAA, Nóbrega PFC, Jeronimo AK, do Nascimento-Filho JM, et al. Active surveillance of Hansen's disease (leprosy): importance for case finding among extra-domiciliary contacts. PLoS Negl Trop Dis. 2013;7(3):e2093.

36. Gauy JS, Hino P, Santos CB. Distribuição espacial dos casos de hanseníase no município de Ribeirão Preto no ano de 2004. Rev Latino-Am Enferm. 2007;15(3):460-5.

37. Duarte-Cunha M, Souza-Santos R, Matos HJ, Oliveira MLW. Aspectos epidemiológicos da hanseníase: uma abordagem espacial. Cad Saúde Pública. 2012;28(6):1143-55.

38. Imbiriba ENB, Silva Neto AL, Souza WV, Pedrosa V, Cunha MG, Garnelo L. Desigualdade social, crescimento urbano e hanseníase em Manaus: abordagem espacial. Rev Saúde Pública. 2009;43(4):656-65.

39. Barreto JG, Bisanzio D, Guimarães LS, Spencer JS, VazquezProkopec GM, Kriton U, et al. Spatial Analysis Spotlighting Early Childhood Leprosy Transmission in a Hyperendemic
Municipality of the Brazilian Amazon Region.PLoS Negl Trop Dis. 2014;8(2):e-2665.

40. Lapa T, Albuquerque MFPM, Carvalho MS, Silveira Jr JC. Análise da demanda de casos de hanseníase aos serviços de saúde através do uso de técnicas de análise espacial. Cad. Saúde Pública. 2006;22(12):2575-83.

41. Queiroz JW, Dias GH, Nobre ML, D e Souza Dias MC, Araújo SF, Barbosa JD, et al. Geographic information systems and applied spatial statistics are efficient tools to study Hansen's disease (leprosy) and to determine areas of greater risk of disease. Am J Trop Med Hyg. 2010;82(2):306-14.

42. Mencaroni DA, Pinto Neto JM, Villa TCS, Oliveira MHP. Análise espacial da endemia hansênica na área urbana do município de Fernandópolis/SP. Hansen Int. 2004;29(1):12-20.

43. Amaral EP, Lana FCF. Análise espacial da Hanseníase na microrregião de Almenara - MG, Brasil. Rev Bras Enferm. 2008;(61):701-7.

44. Cury MRCO, Paschoal VDA, Nardi SMT, Chierotti AP, Rodrigues J Jr AL, Chiaravalloti-Neto F. Spatial analysis of leprosy incidence and associated socioeconomic factors. Rev Saúde Pública. 2012;46(1):110-8.

45. Barreto JG, Bisanzio D, Frade MAC, Moraes TMP, Gobbo AR, de Souza Guimarães L, et al. Spatial epidemiology and serologic cohorts increase the early detection of leprosy. BMC Infect Dis. 2015; 15:527.

46. Garcia DR, Ignotti E, Cortela DCB, Xavier DR, Barelli CSGAP. Análise espacial dos casos de hanseníase, com enfoque à área de risco, em uma unidade básica de saúde no município de Cáceres (MT). Cad Saúde Colet. 2013;21(2):168-72.

47. Paschoal JAA, Paschoal VDA, Nardi SMT, Rosa PS, Ismael MGS, Sichieril EP. Identification of urban leprosy clusters. Scientific World Journal. 2013;2013:219143.

48. Galvão PRS, Ferreira AT, Maciel MGG, Almeida RP, Hinders D, Schreuder PA, et al. Uma avaliação do sistema de informação SINAN usado no Programa de Controle de Hanseníase no estado do Pernambuco, Brasil. Cad. Saúde Coletiva 2009;17(1);87-102.

49. Bovendorp ACC, Oliveira MB, Saleme OS, Lyon S, Bastos M. Qualidade de registros de hanseníase em centro de referência no estado de Minas Gerais, no período de 2006 a 2010. Rev Méd Minas Gerais 2014;24 (Supl 6):S61-S65.

50. Assunção RM, Barreto SM, Guerra HL, Sakurai E. Mapas de taxas epidemiológicas: uma abordagem Bayesiana. Cad Saúde Pública. 1998;14(4):713-23.

51. Bakker MI, Scheelbeek PFD, van Beers SM. The use of GIS in leprosy control. Lepr Rev. 2009;80(3):327-31.

52. Ministério da Saúde. Situação epidemiológica da hanseníase no Brasil - análise de indicadores selecionados na última década e desafios para eliminação. Boletim Epidemiológico. Secretaria de Vigilância em Saúde. 2013; vol. 44(11):1-12.

53. Smith CS, Aerts A, Kita E, Virmond M. Time to define leprosy elimination as zero leprosy transmission? Lancet Infect Dis. 2016;16(4):398-9.

54. Henry M, GalAn N, Teasdale K, Prado R, Amar H, Rays MS, et al. Factors Contributing to the Delay in Diagnosis and Continued Transmission of Leprosy in Brazil - An Explorative, Quantitative, Questionnaire Based Study. PLoS Negl Trop Dis. 2016;10(3):e0004542

55. Penna MLF, Oliveira MLW, Carmo EH, Penna GO, Temporão JG. Influência do aumento do acesso à atenção básica no comportamento da taxa de detecção de hanseníase de 1980 a 2006. Rev Soc Bras Med Trop. 2008;41(suppl II):6-10.

56. San Pedro A, Oliveira RM. Tuberculose e indicadores socioeconômicos: revisão sistemática da literatura. Rev Panam Salud Publica. 2013;33(4):294-301. 